\title{
VIBRATION CHARACTERISTICS OF A SUSPENSION FOOTBRIDGE
}

Dr James Mark William Brownjohn

School of Civil and Structural Engineering,

Nanyang Technological University

Nanyang Avenue,

Singapore 639798

Pages: $\quad 19$

Figures: $\quad 10$

Proofs to Author at above address. 


\section{SUMMARY}

A suspension footbridge located in a tourist attraction in Singapore has a suspended span of $35 \mathrm{~m}$ and was designed for static pedestrian and wind loads. In common with other bridges of this type it is a light, efficient structure and has a lively dynamic performance.

Distributed parameter and finite element models were used to understand the vertical plane behaviour of the bridge and a prototype dynamic test using impact excitation was conducted to check the models and investigate the dynamic response.

This first two vertical vibration modes were found to occur at the same frequency, $2 \mathrm{~Hz}$, as the average pedestrian footfall. Response to pedestrians was simulated using linear and non-linear models of a moving excitation source.

\section{INTRODUCTION}

At the time of writing, the only conventional suspension bridge in service in Singapore is a $35 \mathrm{~m}$ span footbridge located in a tourist attraction. Because such a bridge is unusual in Singapore the design was made to be conservative but the bridge has quite a lively dynamic response. This 'bouncy' bridge is seen as a positive asset, adding to the attraction to visitors. The liveliness is typical of cable supported footbridges [1,2].

Preliminary dynamic investigations from impact testing, heel drop and heavy walking indicated that vertical vibrations were readily excited, lateral vibrations could only be excited with difficulty, and that torsional response was generated only by deliberate effort and was heavily damped.

It was found that vertical plane vibrations at approximately $2 \mathrm{~Hz}$ that could be excited as an antisymmetric mode or a symmetric mode depending on the point of excitation. A single person walking heavily across the bridge could excite noticeable vibrations at this frequency before reaching midspan resulting in a 'floating' sensation while walking across the remaining half span. The nature of the $2 \mathrm{~Hz}$ vertical plane performance was therefore of particular interest due to its coincidence with natural footfall frequency.

The aim of this research has been

a) to explore the liveliness of the bridge experimentally,

b) to set up simple mathematical models representing vertical plane performance,

c) to explore effects of varying structural parameters and tune the models to the experimental results and

d) to compare measured response to a pedestrian with simulation from linear and non-linear models. 


\section{STRUCTURAL ARRANGEMENT}

Figure 1 shows the bridge features. The suspended deck has a $35 \mathrm{~m}$ span and there are no side spans. The deck comprises 3 grade $43229 \times 89 \mathrm{~mm}$ rolled steel channel section stringers with total second moment of area $\mathbf{I}=1.02 \times 10^{8} \mathrm{~mm}^{4}$. Lateral bracing is provided by $152 \times 76 \mathrm{~mm}$ channel section transoms beams welded below the stringers at $3 \mathrm{~m}$ intervals. $70 \times 70 \mathrm{~mm}$ angles span diagonally between transoms. The walkway comprises $25 \mathrm{~mm}$ timber panels supported on the stringers. The handrail system is a vertical unbraced steel frame with uprights welded to the transoms.

The towers comprise rolled steel square and rectangular hollow sections. Each tower upright, $6 \mathrm{~m}$ high, is braced by two diagonal and two horizontal members and is pinned about a lateral axis at the tower footing. Curved machined blocks form the saddles. Each main cable is a $26 \mathrm{~mm}$ diameter fibre core wire rope with a sag of $5.5 \mathrm{~m}$ and a horizontal tension of approximately $30 \mathrm{kN}$ per cable. In the design for static loads the effective cable area $A_{c}$ and (static) modulus $E_{c}$ were taken as $66 \%$ and $30 \%$ respectively of values for solid steel material. The straight backstays are $9.4 \mathrm{~m}$ long, at $30^{\circ}$ to the horizontal. Vertical hangers, at $3 \mathrm{~m}$ intervals, are $16 \mathrm{~mm}$ diameter steel rods, effectively pinned at each end.

The fixity at the end of the deck is uncertain; the deck stringers end at the tower footings, without specific restraint. The handrails continue beyond the towers and offer some restraint to rotation.

The design of the structure, for static loading, was for $31 \mathrm{~m} / \mathrm{sec}$ wind speed, unfactored dead load of $2.14 \mathrm{kN} / \mathrm{m}$ and unfactored live load $5.58 \mathrm{kN} / \mathrm{m}$.

\section{MATHEMATICAL MODELLING}

From preliminary experimental investigations of the behaviour of the bridge, which included excitation by heel-drop, walking and bouncing it was observed that the vertical plane vibrations were the strongest, most interesting and important aspect of the dynamic behaviour. From the experience of analysing and testing several other suspension bridges[2-5] it is clear that the behaviour in the vertical plane is usually modelled with acceptable accuracy using two-dimensional models taking the deck as a beam. This particular bridge has many similarities with the previously tested bridges; it is symmetric, with cables and hangers in parallel vertical planes. The torsional and lateral resistance of the deck in the other bridges has little if any effect on the vertical plane behaviour.

Since the design of the bridge for static loads is conservative, the deck is likely to contribute significantly to the dynamic stiffness. In the complete suspension bridge, since the hangers are stiff, the deck and cable are forced to vibrate together in the 
vertical plane. As separate components the deck and cable would adopt their own vibration patterns so it is interesting to see to what extent the marriage of the deck and cable modifies the natural behaviour of each sub-structure. To this end the bridge was represented as

i) a catenary (i.e. zero deck rigidity)

ii) a beam (i.e. zero cable tension)

iii) bridge; a combination of beam (girder) suspended from the catenary.

Each of these was modelled as a distributed parameter (DP) system using continuum equations and the bridge was also modelled using discrete coordinate or finite elements (FEs). In each case the total mass and stiffness characteristics were collapsed to a single vertical plane representation, ignoring lateral and torsional behaviour.

\section{CONTINUUM EQUATIONS FOR DISTRIBUTED PARAMETER SYSTEM}

For the catenary, the ends are assumed to be fixed and the mass of the deck to be directly transmitted to the cable by inextensible connections. The total load per unit length is $\rho$. In the static configuration the horizontal component of cable tension is $\mathrm{H}$; the time varying part in dynamic response is $\mathrm{h}(\mathrm{t})$. The vertical position with respect to an origin $(x, y=0)$ at the lowest (midspan) point in the cable is $y(x)$ and the time varying part $\mathrm{v}(\mathrm{x}, \mathrm{t})$.

Under static loads, equilibrium is given by

$$
\mathrm{Hy}^{\prime \prime}=\rho
$$

and for dynamic response in free vibration by

$$
(\mathrm{H}+\mathrm{h})(\mathrm{y}+\mathrm{v})^{\prime \prime}=\rho+\rho \ddot{v} / g .
$$

Combining equations (1) and (2), ignoring second order terms, using the midspan sag computed from equation (1) $d=\rho l^{2} / 8 \mathrm{H}$ and using a term -EIv ${ }^{\text {iv }}$ for girder rigidity leads to:

CATENARY:

$$
\mathrm{v}^{\prime \prime}-\frac{\ddot{\mathrm{v}} \rho}{\mathrm{Hg}}=-\frac{8 d \mathrm{~h}}{\mathrm{H} l^{2}}
$$

BEAM:

BRIDGE:

$$
\begin{aligned}
& -\frac{\ddot{\mathrm{v}} \rho}{\mathrm{g}}-\mathrm{EIv}^{\mathrm{iv}}=0 \ldots \\
& -\frac{\ddot{\mathrm{v}} \rho}{\mathrm{Hg}}-\frac{\mathrm{EIv}^{\mathrm{iv}}}{\mathrm{H}}=-\frac{8 d \mathrm{~h}}{\mathrm{H} l^{2}}
\end{aligned}
$$

Assuming a solution of the form $v(x, t)=\hat{v(x)} \mathrm{e}^{j \omega t}, h(t)=\hat{h}^{j \omega t}$ and defining $\beta^{2}=\rho \omega^{2} / \mathrm{Hg}$ with $\omega=2 \pi \mathrm{f}$, the general solution for equation $(3 \mathrm{c})$ is 


$$
\left.\widehat{\mathrm{v}(\mathrm{x})}=\mathrm{A} \cosh \left(\mathrm{p}_{1} \mathrm{x}\right)+\mathrm{B} \sinh \left(\mathrm{p}_{1} \mathrm{x}\right)+\mathrm{C} \cos \left(\mathrm{p}_{2} \mathrm{x}\right)+\mathrm{D} \sin \left(\mathrm{p}_{2} \mathrm{x}\right)-8 d \hat{\mathrm{h}} /(\beta l)^{2} \mathrm{H} \ldots 4\right)
$$

where $\mathrm{p}_{1}, \mathrm{p}_{2}$ are

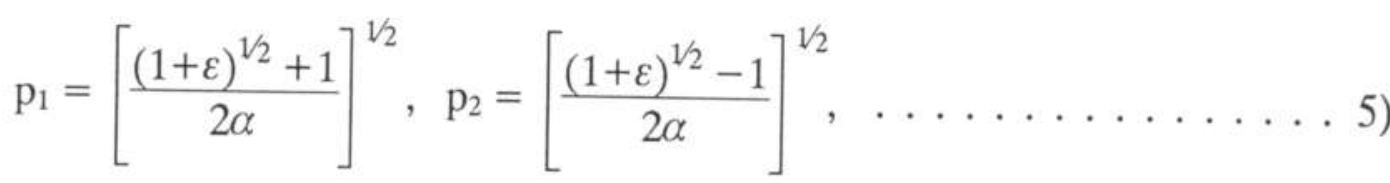

$\alpha=\mathrm{EI} / \mathrm{H}$ and $\varepsilon=4 \alpha \beta^{2}$. Natural frequencies are then

$$
\mathrm{f}=\frac{\beta}{2 \pi}\left(\frac{\mathrm{Hg}}{\rho}\right)^{1 / 2} .
$$

For the catenary of equation (3a), hyperbolic terms in equation (4) vanish and equation (5) becomes $\mathrm{p}_{2} \equiv \beta$. Standard solutions for the catenary, equation (3a,) and beam, equation (3b), and are readily available $[6,7]$.

Solutions for natural frequencies are obtained by applying appropriate boundary conditions on (4), to determine the constants A-D in terms of $\beta$ and solving the resulting frequency equations for roots $\beta_{\mathrm{i}}$. For beam and bridge the boundary conditions of end curvature and/or slope are applied. For bridge symmetric modes it is also necessary to consider the effect of the tower and backstay via a boundary condition linking longitudinal motion of the cable and oscillating main cable tension. Mode shapes for mode i $\varphi_{\mathrm{i}}(\mathrm{x})$ are particular forms of equation (4) obtained by substituting for $\beta_{\mathrm{i}}$.

The solutions for frequency and mode shape are given in Appendix 1 and the particular values of frequency obtained with design values are given in Table 1 for the first antisymmetric mode (denoted as VA1 with natural frequency fVA1) and the first symmetric mode (denoted as VS1 with natural frequency fVS1). 
Table 1 Natural frequencies according to structure and end fixity

\begin{tabular}{|c|c|c|c|c|}
\hline & & pinned: $\mathrm{v}^{\prime \prime}=0$ & sprung: $\mathrm{v}^{\prime \prime}=\mathrm{k}_{\mathrm{r}} \mathrm{v}^{\prime}$ & clamped: $\mathrm{v}^{\prime}=0$ \\
\hline \multirow{5}{*}{$\frac{\mathrm{fvS} 1}{\mathrm{~Hz}}$} & cable & \multicolumn{3}{|l|}{0.672} \\
\hline & beam & 0.396 & - & 0.898 \\
\hline & bridge (DP) & 1.682 & 1.750 & 1.771 \\
\hline & bridge (2D-FE) & 1.687 & 1.755 & 1.772 \\
\hline & bridge (3D-FE) & 1.634 & - & 1.726 \\
\hline \multirow{5}{*}{$\frac{\text { fVA1 }}{\mathrm{Hz}}$} & cable & \multicolumn{3}{|l|}{0.472} \\
\hline & beam & 1.585 & & 2.476 \\
\hline & bridge (DP) & 1.654 & 2.313 & 2.528 \\
\hline & bridge (2D-FE) & 1.647 & 2.282 & 2.490 \\
\hline & bridge (3D-FE) & 1.654 & - & 2.491 \\
\hline
\end{tabular}

Columns labelled $\mathrm{v}^{\prime \prime}=\mathrm{k}_{\mathrm{r}} \mathrm{v}^{\prime}$ are where the uncertain fixity at each deck end is represented by a variable rotational restraint $\mathrm{k}_{\mathrm{r}}$ corresponding to a rotational spring $\mathrm{k} \theta=\mathrm{k}_{\mathrm{r}} \mathrm{EI}$. A value $\mathrm{k}_{\mathrm{r}}=1.0$ was assumed initially, there being no direct way to measure its value. The pinned and clamped conditions correspond to $\mathrm{k}_{\mathrm{r}}=0$ and $\mathrm{k}_{\mathrm{r}}=\infty$.

\section{Antisymmetric modes}

Figure 2 shows mode shapes corresponding to the frequencies given in Table 1; modes for pinned beam, bridge or catenary are indistinguishable from each other, as are the two clamped modes. For the same end fixity the bridge natural frequencies are only slightly higher than for beam alone. The cable makes little contribution to the bridge dynamic stiffness as it is relatively flexible for the antisymmetric modes; which are essentially beam vibration modes. The antisymmetry implies zero variation of cable tension and hence no deflection of the tower, so (to first order) the backstay is not a factor in these modes.

\section{Symmetric modes}

The symmetric modes have more complex solutions since, unlike antisymmetric modes, there will be significant cable stretching and oscillating tension $\mathrm{h}$.

Figure 3 shows the mode shapes corresponding to the frequencies given in Table 1. The much increased stiffness of the combination (the top three values and shapes in Figure 3 ) as compared to either beam or catenary on their own (the lower three values and shapes in Figure 3 ) is because the cable is forced into a zero-node pattern which requires significant cable stretching over the natural double-node pattern for cable alone. 


\section{DISCRETIZED (FINITE ELEMENT) MODEL}

The same parameters were used in a two-dimensional (2D) FE model developed [8] to explore non-linear effects in suspension bridges. Frequencies for VS1 and VA1 for the same end conditions used in the DP model $\left(\mathrm{k}_{\mathrm{r}}=0, \mathrm{k}_{\mathrm{r}}=1\right.$ and $\left.\mathrm{k}_{\mathrm{r}}=\infty\right)$ are given in Table 1.

In the FE model the mass is lumped at the nodes, which are at the connections between hangers and the deck or cables, together with tower base and tip and the backstay anchorage. The stiffness matrix $\mathbf{K}$ comprises an elastic component $\mathbf{K}_{\mathrm{e}}$ and a geometrically non-linear gravity stiffness $\mathbf{K}_{\mathrm{g}}$ due to the axial loads in cables and hangers. Although for this bridge the hangers are stiff, the model allows for hangers that do not take axial compressive loads. As in the DP model, the FE representation collapses the two cable planes into one. The model has only 33 degrees of freedom.

As a check on the accuracy of the $2 \mathrm{D}$ model in representing a three dimensional structure, a full three dimensional (3D) model was set up using SAPIV and ANSYS codes. Figure 4 shows the 3D mesh and the equivalent 2D mesh. Figure 5 shows some mode shapes generated by the 3D solution for the pinned deck condition $\left(\mathrm{k}_{\mathrm{r}}=0\right)$ : Modes VS1 and VA1 together with the fundamental lateral and torsional modes LS1 and TS1 are shown. As there is minimal difference between vertical modes from 3D and $2 \mathrm{D}$ solutions (even for more complex multi-noded mode shapes) the simple 2D model is used in the correlation.

The 2D- FE frequencies are close enough to the DP frequencies that the models can be used in parallel. While values of either fVA1 or fVS1 are almost the same between DP and FE model, both are far too low compared with experimental estimates, showing the need to modify the parameters in the models. The effects of varying structural parameters were explored using both models.

The parameters length $(l), \operatorname{sag}(d)$, horizontal tension $(\mathrm{H})$, load $(\rho)$ and backstay length $\left(l_{\mathrm{s}}\right)$ are known accurately leaving the following uncertainties.

1) I for the deck, since no account is made for handrail or other steelwork.

2) $E_{c}$ for the main cable and backstay, since the design value is rather conservative.

3) the rotational constraint $\mathrm{k}_{\mathrm{r}}$ at the deck end.

These are seen as independent parameters in the frequency equations (Appendix 1). Updating of three parameters in a model via system identification requires experimental measurement of at least three values. A prototype test was conducted to determine a set of at least three natural frequencies and mode shapes. 


\section{PROTOTYPE TESTING}

The preliminary testing which highlit the peculiar response at $2 \mathrm{~Hz}$ also showed the need for a form of prototype testing able to define clearly the modal characteristics of the bridge. Hammer testing [9] was used, being an ideal method for a structure of this size and having several advantages over other possible methods; the equipment is simple and portable, requiring no mains power supply and each impact provides wideband load with good signal to noise ratio in the response so that the frequency response function (FRF) between excitation and response points can be determined with just a few hammer blows.

Some factors that improve the quality of data obtained from prototype testing are:

1) High quality accelerometers should be used, having response signal well above instrument noise.

2) Low pass filters should be used to remove unwanted high amplitude high frequency transients, to obtain maximum benefit from recorder/analyser dynamic range.

3) The Force (transient)/Response (exponential) windows should be used carefully to minimise ambient noise effects.

In this test, a 16 pound $(7.25 \mathrm{~kg})$ instrumented hammer, amplifier and low pass filter (Dytran), a pair of accelerometers (Allied Signal QA-700) with home-built signal conditioning, a DAT tape recorder (TEAC RD120) and dual channel signal analyser (Brüel and Kjær 2148) were used.

Although lateral and torsional modes were measured, the main concern was vertical modes, measured on the deck, by maintaining one accelerometer at the same position and moving the hammer to each of the 11 locations corresponding to hanger terminations and transom beams.

The FRF, as a function of frequency $\omega$ measured between acceleration response at position $\mathrm{b}\left(\ddot{\mathrm{x}}_{\mathrm{b}}\right)$ and force at position $\mathrm{a}\left(\mathrm{p}_{\mathrm{a}}\right)$ is the inertance function

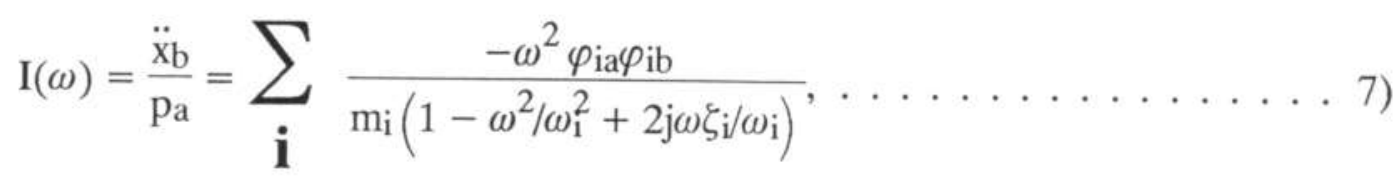

in which $\mathrm{m}_{\mathrm{i}}, \omega_{\mathrm{i}}, \zeta_{\mathrm{i}}$ are respectively modal mass, frequency and damping ratio for mode i.

Because of reciprocity, in theory there is no difference between moving the hammer (vary a) and moving the accelerometer (vary b). In practice, the moving mass of the tester may result in slight modifications to the modal parameters. 
Data were analysed on a $0-25 \mathrm{~Hz}$ base-band, with 801 lines and $0.0312 \mathrm{~Hz}$ resolution. Force $\left(0.2\right.$ second duration $\left.\mathrm{T}_{\mathrm{F}}\right)$ and response ( 4 second time constant $\left.\mathrm{T}_{\mathrm{R}}\right)$ windows were used, taking an average of four hammer impacts.

As well as hammer testing, modes VS1 and VA1 were excited by jumping followed by free decay in order to provide damping estimates directly from the logarithmic decrement. Finally the response due to a single pedestrian crossing the bridge was recorded.

\section{EXPERIMENTAL MODAL CHARACTERISTICS}

A set of 11 FRFs, corresponding to each of the measurement locations, were analysed using both ICATS[10] and MDOF[11] modal analysis software. The imaginary component of $\mathrm{I}(\omega)$ (Figure 6) clearly shows the presence of two very close modes, in antiphase for this particular combination of positions $a$ and $b$.

Figure 7 shows measured mode shapes $\left(\varphi_{\mathrm{ia}}\right)$ for the lowest five measured modes $(i=1 \rightarrow 5)$ and eleven excitation positions (a) together with frequencies and damping ratios. Figure 6 indicates a sixth mode at approximately $11.1 \mathrm{~Hz}$ which has a mode shape almost indistinguishable from that of mode VS3 and which was not generated in any of the models.

Damping ratio estimates $\xi_{\text {est }}$ for the 3 higher modes were obtained from ICATS with a correction for the effect of the response window: $\zeta_{\text {est }}=\zeta_{\text {ICATS }}-1 / 2 \pi f T_{R}$. Values $\zeta_{\text {est }}$ for the fundamental symmetric and antisymmetric modes were obtained from the tail ends of the free decay response from large oscillations induced by jumping.

Figure 8 shows values of $\zeta$ obtained for mode VA1 via logarithmic decrement. The values decrease from $1.8 \%$ for a peak to peak $1 / 4$ span amplitude of $35 \mathrm{~mm}$ to $1 \%$ at low amplitude. Likewise for VS1 the lowest value obtained was $1 \%$.

\section{TORSIONAL AND LATERAL RESPONSE}

Measurements of lateral and torsional response were made for reference, but as mentioned previously the modes were not so easily excited and therefore not the critical concern.

Two torsional modes were identified; an antisymmetric mode (TA1) at $1.84 \mathrm{~Hz}$ with approximately $2.4 \%$ damping and a symmetric mode (TS1) at $2.52 \mathrm{~Hz}$ with approximately $1.4 \%$ damping. The fundamental lateral mode (LS1) at $1.25 \mathrm{~Hz}$ was found to be symmetric and very heavily damped.

Comparison with the 3D solution (Figure 5) show reasonable agreement for LS1. In fact, assuming no restraint on rotation about a vertical axis at the deck ends, mode LS1 frequency depends heavily on the effectiveness of the diagonal bracing. 
The 3D model collapses the stringers, transoms, diagonal bracing and handrail into a horizontal plane which under-values the rotational inertia and overemphasises the stiffness of the steel frame and its connections in torsion so the predicted TA1 and TS1 frequencies are bound to be too high. Even so it is surprising that the antisymmetric modes TA1 appears at the lower frequency.

\section{SYSTEM IDENTIFICATION}

Based on the initial theoretical estimates and the measured natural frequencies, the parameters $\mathrm{I}, \mathrm{E}_{\mathrm{c}}$ and $\mathrm{k}_{\mathrm{r}}$ were adjusted to obtain a good fit between the experimental values for the first five vertical mode natural frequencies and those obtained from the 2D FE model.

The least squares procedure [12] was used:

If the prior estimates of structural parameters ( $\mathrm{I}, \mathrm{E}_{\mathrm{c}}, \mathrm{k}_{\mathrm{r}}$ ) are assembled into a column vector $\mathbf{r}_{0}$, the $\mathrm{FE}$ values of natural frequencies obtained using $\mathbf{r}_{0}$ are written as a column vector $\mathbf{y}_{0}$ and the experimental (exact) values of natural frequency are written as $\mathbf{y}_{\mathrm{e}}$, then for small differences between experimental and FE values the 'correct' values of the parameters $\mathbf{r}$ are found using

$$
\mathbf{y}_{0}-\mathbf{y}_{\mathrm{e}}=\mathbf{T}\left(\mathbf{r}_{0}-\mathbf{r}\right)
$$

or $\mathbf{Y}=\mathbf{T R}$, where $\mathbf{T}$ is a sensitivity matrix with terms $\partial \mathrm{y}_{\mathrm{k}} / \partial \mathrm{r}_{\mathrm{i}}, \quad \mathrm{i}=1 \rightarrow 3, \mathrm{k}=1 \rightarrow 5$. The iteration scheme to find $\mathbf{r}$ via $\mathbf{R}=\mathbf{T}^{-1} \mathbf{Y}$ becomes

$$
\mathbf{r}_{\mathrm{n}+1}=\mathbf{r}_{\mathrm{n}}-\mathbf{T}^{-1}\left(\mathbf{y}_{\mathrm{n}}-\mathbf{y}_{\mathrm{e}}\right)
$$

Since $\mathbf{T}$ is a $5 \times 3$ matrix the pseudoinverse $\left(\mathbf{T}^{\mathrm{T}} \mathbf{T}\right)^{-1} \mathbf{T}^{\mathrm{T}}$ was used, which is equivalent to a least squares minimisation.

The effective cable area was maintained at $66 \%$ of solid value i.e. $708 \mathrm{~mm}^{2}$ while better starting values of $\mathrm{E}_{\mathrm{c}}$ and $\mathrm{k}_{\mathrm{r}}$ were used in the DP model based on the observations, from Table 1 and Appendix 1, that fvs 1 is too low and increases with $\mathrm{E}_{\mathrm{c}}$, while $\mathrm{k}_{\mathrm{r}}$, which affects fVA1, lies somewhere between 0.0 and 1.0. Initial values in $\mathbf{r}_{0}$ were thus:

$\mathrm{E}_{\mathrm{c}}=100 \mathrm{kN} / \mathrm{mm}^{2}, \quad \mathrm{k}_{\mathrm{r}}=0.3, \quad \mathrm{I}=1.020 \times 10^{8} \mathrm{~mm}^{4}$.

After three iterations with equation (9), each requiring four eigensolutions (to determine $\mathbf{T}$ and the updated $\mathbf{y}$ ), $\mathbf{r}$ converged to:

$\mathrm{E}_{\mathrm{c}}=100.43 \mathrm{kN} / \mathrm{mm}^{2}, \mathrm{k}_{\mathrm{r}}=0.2474, \quad \mathrm{I}=1.1336 \times 10^{8} \mathrm{~mm}^{4}$. 
Table 2 compares natural frequencies (y) using these values with the experimental frequencies and values obtained with equations (A7) and (A14).

The last three columns show the elements of $\mathbf{T}$ as $100 \frac{\mathrm{r}_{i}}{\lambda_{\mathrm{k}}} \frac{\partial \lambda_{k}}{\partial \mathrm{r}_{i}}$, representing the percentage change in mode frequency per $100 \%$ change in parameter. Clearly $\mathrm{E}_{\mathrm{c}}$ is the dominant parameter in mode VS1, for which $\mathrm{k}_{\mathrm{r}}$ has little effect. $\mathrm{E}_{\mathrm{c}}$ has a much smaller influence on other symmetric modes. Girder rigidity $\mathrm{I}$ is the dominant parameter for all other modes, and to a lesser extent $\mathrm{k}_{\mathrm{r}}$.

Table 2 Adjusted theoretical natural frequencies (f) and sensitivities (T)

\begin{tabular}{|l|l|l|l|l|l|l|}
\hline Mode & $\begin{array}{l}\text { Experimental } \\
\text { value } / \mathrm{Hz}\end{array}$ & FE value $/ \mathrm{Hz}$ & DP value $/ \mathrm{Hz}$ & $\begin{array}{l}\partial \mathrm{f} / \partial \mathrm{E}_{\mathrm{c}} \\
(\%)\end{array}$ & $\begin{array}{l}\partial \mathrm{f} / \partial \mathrm{I} \\
(\%)\end{array}$ & $\begin{array}{l}\partial \mathrm{f} / \partial \mathrm{k}_{\mathrm{r}} \\
(\%)\end{array}$ \\
\hline VA1 & 2.072 & 2.110 & 2.142 & 0.00 & $\mathbf{4 6 . 2 4}$ & 11.39 \\
\hline VS1 & 2.151 & 2.149 & 2.146 & $\mathbf{3 9 . 7}$ & 7.58 & 0.60 \\
\hline VS2 & 4.288 & 4.300 & 4.412 & 2.89 & $\mathbf{4 4 . 7 8}$ & 8.07 \\
\hline VA2 & 7.136 & 7.059 & 7.298 & 0.01 & $\mathbf{4 7 . 3 2}$ & 6.22 \\
\hline VS3 & 10.631 & 10.672 & 11.115 & 0.09 & $\mathbf{4 8 . 2 5}$ & 5.08 \\
\hline
\end{tabular}

Mode shapes obtained from equation (A6) and equation (A14) using values in column 4 of Table 2 are shown as the smooth curves in Figure 7. The Modal Assurance Criterion (MAC) values in Figure 7 relate to the closeness of fit between experimental mode shape values and the corresponding mode shapes values from equation (A6) and equation (A14) for the exact measurement points.

\section{SIMULATION OF PEDESTRIAN RESPONSE TIME HISTORIES}

In its context as part of a tourist attraction, the bridge exhibits acceptable behaviour for its users. Its liveliness is not a problem, it is a feature. Where liveliness is not desirable, particularly in a more conventional footbridge having a low fundamental natural frequency $\left(f_{0}\right)$, consideration is usually given to vibration serviceability defined in terms of objective criteria [13-15] for pedestrian comfort.

If pedestrian comfort is an issue, the applicable code in Singapore, BS5400 [13] specifies a vibration limit $0.5\left(\mathrm{f}_{\mathrm{o}}\right)^{1 / 2} \mathrm{~m}_{\mathrm{sec}} \mathrm{ser}^{-2}$ for a single pedestrian, but apparently [15] this is only a recommendation. BS5400 also provides a method of calculating response by approximating a pedestrian as a pulsating dynamic load 


$$
F(t)=180 \sin \left(2 \pi f_{0} t\right) N
$$

moving across the bridge at a speed of $0.9 \mathrm{f}_{\mathrm{o}} \mathrm{m} / \mathrm{sec}$, using the appropriate specified logarithmic decrement $\delta$ which is 0.03 (for steel with asphalt or epoxy surfacing).

The forces generated during walking (running and jumping) are not pure sinusoids and can be modelled as Fourier series of the form [15].

$$
\mathrm{F}(\mathrm{t})=\mathrm{P}\left(1+\sum_{\mathrm{n}=1}^{\mathrm{N}} \alpha_{\mathrm{n}} \sin \left(2 \pi \mathrm{nft}+\varphi_{\mathrm{n}}\right)\right)
$$

in which the fundamental $(\mathrm{n}=1)$ is the strongest with $\alpha_{1} \approx 0.35$ for $\mathrm{f} \approx 2 \mathrm{~Hz}$ giving a pulsating force of $294 \mathrm{~N}$ for a $75 \mathrm{~kg}$ person $(\mathrm{P}=736 \mathrm{~N})$. Equation (10) is equivalent to equation (11) if only the first term is taken, with $\alpha_{1}=0.24$.

Probably $\alpha_{1}$ would be higher if the subject was deliberately walking heavily to excite the bridge; for jumping, $\alpha_{1}$ can be as high as 1.75 . Also the value $\delta=0.03$ $(\xi \approx 0.5 \%)$ is too low, since from measurements $\zeta \geq 1 \%$.

For the DP model, the response is obtained by normal mode analysis, writing

$$
\mathrm{v}(\mathrm{x}, \mathrm{t})=\sum_{\mathrm{i}} \varphi_{\mathrm{i}}(\mathrm{x}) \mathrm{Y}_{\mathrm{i}}(\mathrm{t}) .
$$

Using (3c), with $\rho^{\prime}=\rho / \mathrm{g}$ and constant member properties,

$$
\ddot{\mathrm{v}} \rho^{\prime}-\mathrm{Hv}^{\prime \prime}+\mathrm{EIv}^{\mathrm{iv}}-8 d \mathrm{~h} / l^{2}=\mathrm{F} \delta(\mathrm{x}-\mathrm{vt}) \sin 2 \pi \mathrm{ft} .
$$

The modal response (mode i) is then obtained from:

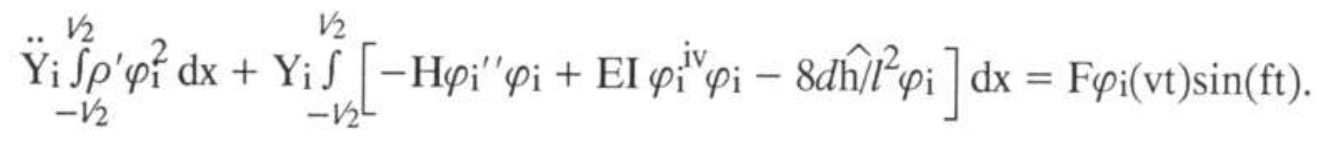

The first integral is the modal mass $m_{\mathrm{i}}$, the second is the modal stiffness $k_{\mathrm{i}}\left(=m_{\mathrm{i}} \omega_{1}^{2}\right)$, for mode i. Adding a damping term,

$$
m_{\mathrm{i}}\left(\ddot{\mathrm{Y}}_{\mathrm{i}}+2 \zeta_{\mathrm{i}} \omega_{\mathrm{i}} \dot{\mathrm{Y}}_{\mathrm{i}}+\omega_{1}^{2} \mathrm{Y}_{\mathrm{i}}\right)=\mathrm{F} \varphi_{\mathrm{i}}(\mathrm{vt}) \sin 2 \pi \mathrm{ft}
$$

For the first pinned antisymmetric mode $\left(\mathrm{h}=0, \quad \varphi_{1}(\mathrm{x})=\sin 2 \pi \mathrm{x} / l\right)$,

$$
\frac{\rho^{\prime} \mathrm{L}}{2}\left(\ddot{\mathrm{Y}}+2 \xi \omega \dot{\mathrm{Y}}+\omega^{2} \mathrm{Y}\right)=\mathrm{F} \sin \frac{2 \pi \mathrm{vt}}{l} \sin 2 \pi \mathrm{ft} .
$$

Variations of equation (16) with different modal mass and more complex functions $\varphi_{\mathrm{i}}(\mathrm{x})$ (as in Appendix 1) to replace $\sin (2 \pi \mathrm{vt} / l)$ will apply for other end conditions and symmetric modes and the response for two modes together can be obtained by superposition.

Response to a moving pedestrian was simulated first using VS1 and VA1 mode shapes from Appendix 1 in a Duhammel integral with equation (16) and second using the 
non-linear FE model with $\alpha_{1}=0.35, \xi=1 \%$. The following peak acceleration values $\left(\mathrm{m} / \mathrm{sec}^{2}\right)$ results were obtained:

$\begin{array}{llll} & 1 / 4 \text { span } & \text { midspan } & 3 / 4 \text { span } \\ \text { DP } & 3.34 & 3.09 & 3.34 \\ \mathrm{FE} & 2.71 & 2.55 & 2.28 \\ \mathrm{FE}+\mathrm{m}_{\mathrm{t}} & 2.42 & 2.28 & 2.19\end{array}$

Measured maximum value (at 3/4 span): $2.18 \mathrm{~m} / \mathrm{sec}^{2}$

The last row is for a non-linear simulation in which the mass $\mathrm{m}_{\mathrm{t}}$ of the pedestrian accelerating at $\ddot{v}_{t}$ is added in as a forcing term $-m_{t} \ddot{v}_{t}$. For the FE simulations the walking frequency is taken as the average of fVA1 and fVS1.

It is worth noting that for all but the largest amplitudes oscillations[8] the vertical plane vibrations of a suspension bridge with invariant mass are well represented by models linearised about the dead load condition. The most significant nonlinearities are lilely to come from the various mechanisms that constitute 'structural damping'[16].

Figure 9 shows actual acceleration response measured with a pedestrian $(75 \mathrm{~kg}$ student tester) walking briskly and heavily across the bridge in the direction from $1 / 4$ span to $3 / 4$ span and Figure 10 shows the acceleration time histories generated in the non-linear simulation $\left(\mathrm{FE}+\mathrm{m}_{\mathrm{t}}\right)$. Figure $9 \mathrm{a}, 10 \mathrm{a}$ are $1 / 4$ span response, $9 \mathrm{~b}, 10 \mathrm{~b}$ are $3 / 4$ span response. Figure 9c, 10c and Figure 9d, 10d are respectively the half-sum and half-difference of the $1 / 4$ span and $3 / 4$ span, intended to represent response in mode VS1 and mode VA1 respectively. Comparison of Figure 9 and Figure 10 suggests an underestimation of damping and walking speed (i.e. stride) in the simulation.

Note that since the response is almost entirely due to $2 \mathrm{~Hz}$ modes, the accelerations can be converted approximately to displacements (in $\mathrm{mm}$ ) by multiplying by $9810 / \omega^{2} \approx 62$.

None of the simulations consider the variable damping (Figure 9) or the flexibility and damping capacity of the pedestrian. In the DP simulation fVA1 and fVS1 are practically identical and the response is dominated by mode VS1 response.

\section{DISCUSSION AND CONCLUSIONS}

Simple two-dimensional finite element (FE) and distributed parameter (DP) models can be used to study the dynamics of the critical vertical plane response of the bridge and produce very similar estimates of bridge modes. Depending on computer implementation (these models were run on a PC) the FE model has the slight 
advantage in terms of ease of studying the effect of different parameters on several modes at once.

The DP model is very useful for predicting fvs 1 and fVA1 alone. From studying these results it is clear that the cable axial stiffness is most important for the first symmetric mode (VS1), and apart from this the other modes are similar to those of a beam with partially fixed ends. This is reflected in the FE system identification sensitivity matrix.

The coincidence of fVS1 and fVA1 at a typical footfall frequency accounts for the relatively high response of the bridge despite its conservative rigidity. In usual usage passage of several pedestrians would reduce the additive effect of modes and alter the dynamic characteristics. When modelling the response to a pedestrian the response depends very much on the closeness of the two modes and the walking characteristics.

The issue of serviceability is of course very important for this type of bridge. Clearly it is lively and since part of its function is to induce tourists to come and enjoy its bouncy behaviour it is definitely serviceable.

Were it desirable, tuning of the bridge to adjust vertical plane natural frequencies upwards or downwards could be done via the girder rigidity and cable stiffness. Another parameter is the length of backstay which would affect mode VS1 the most. For an existing bridge, frequencies could be altered by adjusting handrail continuity at deck ends, or by adding mass at strategic points. Use of discrete dampers [15] would probably be less viable for this type of bridge since they would require maintenance.

\section{ACKNOWLEDGEMENTS}

The author wishes to thank NTU final year students Kho Chza-Main and Chin Yong-Pheng for the very capable execution of the experimental work, Dr Cheng Wen-Haur, Mr Bernard Harrison and Mr Michael Graetz of Singapore Zoological Gardens for their assistance and Mr Philip Chalk of Works Consultancy for providing the design information. 


\section{REFERENCES}

1 R. L. Pimentl, P. Waldron, W. J. Harvey 1995 Analysis and Testing of Bridges. Joint SECED/I. Struct. E Seminar, I. Struct. E, London, 26/4/1995 Assessment of the dynamic behaviour of Aberfeldy glass reinforced plastic cable-stayed footbridge.

2 J. M. W. Brownjohn, A. A. Dumanoglu and C. A. Taylor 1994 Engineering Structures 16, 401-415. Dynamic investigation of a suspension footbridge.

3 J. M. W. Brownjohn, A. A. Dumanoglu, R. T. Severn and C. A. Taylor 1987 Proceedings, Institution of Civil Engineers, Part 2 83, 561-600. Ambient vibration measurements of the Humber Suspension Bridge and comparison with calculated characteristics.

4 J. M. W. Brownjohn, A. A. Dumanoglu, R. T. Severn and A. Blakeborough 1989 Earthquake Engineering and Structural dynamics 18, 263-283. Ambient vibration survey of the Bosporus Suspension Bridge.

5 J. M. W. Brownjohn, A. A. Dumanoglu and R. T. Severn 1992 Earthquake Engineering and Structural dynamics 21, 907-924. Ambient vibration survey of the Fatih Sultan Mehmet (Second Bosporus) Suspension Bridge.

6 H. M. Irvine, T. K. Caughey 1974 Proceedings, Royal Society London A 341, 299-315. The linear theory of the free vibration of a suspended cable.

7 R. D. Blevins 1979 Formulas for natural frequency and mode shape. Krieger.

8 J. M. W. Brownjohn 1994 Earthquake Engineering and Structural Dynamics 23, 1351-1367. Observations on non-linear dynamic characteristics of suspension bridges

9 J. R. Maguire 1984 PhD thesis, University of Bristol Dept. of Civil Engineering Assessing the dynamic properties of prototype structure by hammer testing.

10 Imperial College of Science, Technology and Medicine, London MODENT Reference Manual, Imperial College Analysis Testing and Software. 
11 J. M. W. Brownjohn 1992 Earthquake Engineering Research Centre, University of Bristol TI 23008: Modal analysis of MDOF systems with particular reference to base excitation.

12 J. D. Collins, G. C. Hart, T. K. Hasselman and B. Kennedy 1974 ALAA Journal 12. Statistical identification of structures.

13 British Standards Institution 1978 Steel concrete and composite bridges. Part 2. Specification for loads. BS5400: Part 2: 1978.

14 J. H. Rainer, G. Pernica and D. E. Allen 1988 Canadian Journal of Civil Engineering 15, 66-71. Dynamic loading and response of footbridges.

15 R. T. Jones, A. J. Pretlove and R. Eyre 1981 The Structural Engineer 59B, 27-32. Two case studies in the use of tuned vibration absorbers on footbridges.

16 J. M. W. Brownjohn 1994 Proceedings, Institution of Civil Engineers, Structures and Buildings 104, 401-415. Estimation of damping in suspension bridges. 


\section{APPENDIX 1 NATURAL FREQUENCIES AND MODE SHAPES FROM CONTINUUM EQUATIONS}

The starting point in determining frequencies and mode shapes is the solution of equation (3c):

$$
\widehat{v}(\mathrm{x})=A \cosh \left(\mathrm{p}_{1} \mathrm{x}\right)+\mathrm{B} \sinh \left(\mathrm{p}_{1} \mathrm{x}\right)+\mathrm{C} \cos \left(\mathrm{p}_{2} \mathrm{x}\right)+\mathrm{D} \sin \left(\mathrm{p}_{2} \mathrm{x}\right)-8 d \hat{\mathrm{h}} /(\beta l)^{2} \mathrm{H}
$$

\section{ANTISYMMETRIC MODES}

For antisymmetric modes symmetry requires that $\mathrm{A}=\mathrm{C}=\widehat{\mathrm{h}}=0$ leaving

$$
\widehat{\mathrm{v}(\mathrm{x})}=\mathrm{B} \sinh \left(\mathrm{p}_{1} \mathrm{x}\right)+\mathrm{D} \sin \left(\mathrm{p}_{2} \mathrm{x}\right)
$$

Pinned girder

Boundary conditions are $\mathrm{v}( \pm l / 2)=\mathrm{v}^{\prime \prime}( \pm l / 2)=0$ leading to $\mathrm{B}=0$ and a frequency equation

$$
\sin \left(\mathrm{p}_{2} l / 2\right)=0
$$

with mode shapes, for unit $\mathrm{D}$ and values of $\mathrm{p}_{2}$ satisfying equation $\mathrm{A} 3$

$$
\varphi(\mathrm{x})=\sin \left(\mathrm{p}_{2} \mathrm{x}\right)
$$

Clamped girder

Boundary conditions are $\mathrm{v}( \pm l / 2)=\mathrm{v}^{\prime}( \pm l / 2)=0$ leading to a frequency equation

$$
\tan \left(\mathrm{p}_{2} l / 2\right)=\left(\frac{\mathrm{p}_{2}}{\mathrm{p}_{1}}\right) \tanh \left(\mathrm{p}_{1} l / 2\right)
$$

with mode shapes, for unit D and $\beta$ satisfying equation (A5)

$$
\varphi(\mathrm{x})=\sin \left(\mathrm{p}_{2} \mathrm{x}\right)-\frac{\sin \left(\mathrm{p}_{2} l / 2\right)}{\sinh \left(\mathrm{p}_{1} l / 2\right)} \sinh \left(\mathrm{p}_{1} \mathrm{x}\right)
$$

Girder with rotational springs

Boundary conditions are $\mathrm{v}( \pm l / 2)=0, \mathrm{v}^{\prime \prime}(-l / 2)=\mathrm{kr}_{\mathrm{r}}{ }^{\prime}(-l / 2), \mathrm{v}^{\prime \prime}(l / 2)=-\mathrm{kr}_{\mathrm{r}} \mathrm{v}^{\prime}(l / 2)$, with $\mathrm{k}_{\mathrm{r}}=\mathrm{k}_{\theta} / \mathrm{EI}$ leading to a frequency equation

$$
\mathrm{p}_{2} \cot \left(\mathrm{p}_{2} l / 2\right)-\mathrm{p}_{1} \operatorname{coth}\left(\mathrm{p}_{1} l / 2\right)=\frac{(1+\varepsilon)^{1 / 2}}{\alpha \mathrm{k}_{\mathrm{r}}} .
$$

with mode shapes given by equation (A6) for $\beta$ satisfying equation ( A7).

Equation (A3) and equation (A5) are special cases of equation (A7) when, respectively, $\mathrm{k}_{\mathrm{r}}=0$ and $\mathrm{k}_{\mathrm{r}}=\infty$. 


\section{SYMMETRIC MODES}

For symmetry, $\mathrm{B}, \mathrm{D}=0$ but the oscillating component of tension $\hat{\mathrm{h}}$ is not required to be zero i.e.

$$
\widehat{\mathrm{v}(\mathrm{x})}=\mathrm{A} \cosh \left(\mathrm{p}_{1} \mathrm{x}\right)+\mathrm{C} \cos \left(\mathrm{p}_{2} \mathrm{x}\right)-8 d \hat{\mathrm{h}} /(\beta l)^{2} \mathrm{H}
$$

Solutions are more complex than for the antisymmetric modes since cable stretching due to the non zero $\hat{h}$ has to be taken into account via the 'cable equation' [6] which in this case leads to:

$$
\frac{\hat{\mathrm{h}} \mathrm{l}_{\mathrm{e}}}{\mathrm{E}_{\mathrm{c}} \mathrm{A}_{\mathrm{c}}}=\left[\begin{array}{l}
+l / 2 \\
-l / 2
\end{array}-\int_{-l / 2}^{+l / 2} \mathrm{y}^{\prime \prime} \hat{\mathrm{v}} \mathrm{dx}\right.
$$

where 'virtual cable length' $l_{e} \approx l\left(1+8(\mathrm{~d} / l)^{2}\right), \mathrm{E}_{\mathrm{c}}, \mathrm{A}_{\mathrm{c}}$ are cable modulus and sectional area, and $\widehat{\mathrm{u}(\mathrm{x})}$ is the longitudinal deflection.

The frequency equations are obtained by determining A and C in equation (A8) in terms of $\hat{\mathrm{h}}$ via the boundary conditions then substituting equation (A8) into equation (A9). In addition the effect of the backstay length $l_{\mathrm{s}}$ and inclination $\theta$ can be approximated by a spring $\mathrm{k}_{\mathrm{S}}=\mathrm{E}_{\mathrm{c}} \mathrm{A}_{\mathrm{c}} \cos ^{2} \theta / l_{s}$ such that

$$
\hat{\mathrm{u}}(l / 2)-\hat{\mathrm{u}}(-l / 2)=\hat{2 h} / \mathrm{k}_{\mathrm{s}}
$$

Pinned girder

$$
\frac{(\beta l)^{2}}{\lambda^{2}}\left\{1+\frac{2 l_{s}}{\cos ^{2} \theta l \mathrm{e}}\right\}=1-\left(\frac{2}{\mathrm{p}_{2} l}\right) \frac{\left[\tan \left(\mathrm{p}_{2} l / 2\right)+\left(\mathrm{p}_{2} / \mathrm{p}_{1}\right)^{3} \tanh \left(\mathrm{p}_{1} l / 2\right)\right]}{\left(1+\left(\mathrm{p}_{2} / \mathrm{p}_{1}\right)^{2}\right)}
$$

where $\lambda^{2}=\mathrm{E}_{\mathrm{c}} \frac{\mathrm{A}_{\mathrm{c}}}{\mathrm{H}} \frac{l}{l_{e}}\left(\frac{8 d}{l}\right)^{2}$.

\section{Clamped girder}

$$
\frac{(\beta l)^{2}}{\lambda^{2}}\left\{1+\frac{2 l_{s}}{\cos ^{2} \theta l_{\mathrm{e}}}\right\}=1-\left(\frac{2}{\mathrm{p}_{2} l}\right) \frac{\left(1+\left(\mathrm{p}_{2} / \mathrm{p}_{1}\right)^{2}\right)}{\left[\cot \left(\mathrm{p}_{2} l / 2\right)+\left(\mathrm{p}_{2} / \mathrm{p}_{1}\right) \operatorname{coth}\left(\mathrm{p}_{1} l / 2\right)\right]}
$$

Girder with rotational springs

$$
\frac{(\beta l)^{2}}{\lambda^{2}}\left\{1+\frac{2 l_{s}}{\cos ^{2} \theta l_{\mathrm{e}}}\right\}=1-\left(\frac{2}{\mathrm{p}_{2} l}\right) \frac{\left(\sin \left(\mathrm{p}_{2} l / 2\right)+\left(\mathrm{p}_{2} / \mathrm{p}_{1}\right) \gamma \sinh \left(\mathrm{p}_{1} l / 2\right)\right)}{\left(\cos \left(\mathrm{p}_{2} l / 2\right)+\gamma \cosh \left(\mathrm{p}_{1} l / 2\right)\right)}
$$

where $\gamma=\left(\frac{\mathrm{p}_{2}}{\mathrm{p}_{1}}\right) \frac{\left(\mathrm{k}_{\mathrm{r}} \sin \left(\mathrm{p}_{2} l / 2\right)+\mathrm{p}_{2} \cos \left(\mathrm{p}_{2} l / 2\right)\right)}{\left(\mathrm{k}_{\mathrm{r}} \sinh \left(\mathrm{p}_{1} l / 2\right)+\mathrm{p}_{1} \cosh \left(\mathrm{p}_{1} l / 2\right)\right)}$.

Equation (A11) and equation (A12) are special cases of equation (A13) when, respectively, $\mathrm{k}_{\mathrm{r}}=0$ andk $\mathrm{k}_{\mathrm{r}}=\infty$. 
Mode shapes for the symmetric modes are given by using appropriate values of $\gamma$ and $\beta$ satisfying equations (A11-A13):

$$
\varphi(\mathrm{x})=\frac{8 d \hat{\mathrm{h}}}{(\beta l)^{2}}\left\{\frac{\cos \left(\mathrm{p}_{2} \mathrm{x}\right)+\gamma \cosh \left(\mathrm{p}_{1} \mathrm{x}\right)}{\cos \left(\mathrm{p}_{2} l / 2\right)+\gamma \cosh \left(\mathrm{p}_{1} l / 2\right)}-1\right\}
$$

For a catenary with fixed ends, $l_{s}=0, \mathrm{p}_{2}=\beta, \gamma=0$ and then equations (A11-A13) lead to the frequency equation

$$
\left(\frac{\beta l}{2}\right)^{2} \frac{4}{\lambda^{2}}=1-\left(\frac{2}{\beta l}\right) \tan \left(\frac{\beta l}{2}\right) \text {. }
$$

Finally, in the symmetric mode, the tower tip displacement is related to the midspan displacement by

$$
\widehat{\mathrm{u}}(-l / 2)=\varphi(0) \frac{\mathrm{H} \beta^{2} l_{s}}{\mathrm{E}_{\mathrm{c}} \mathrm{A} \rho_{\mathrm{c}} \cos ^{2} \theta} \frac{1+\gamma}{\left(\cos \left(\mathrm{p}_{2} l / 2\right)+\gamma \cosh \left(\mathrm{p}_{1} l / 2\right)\right)}
$$



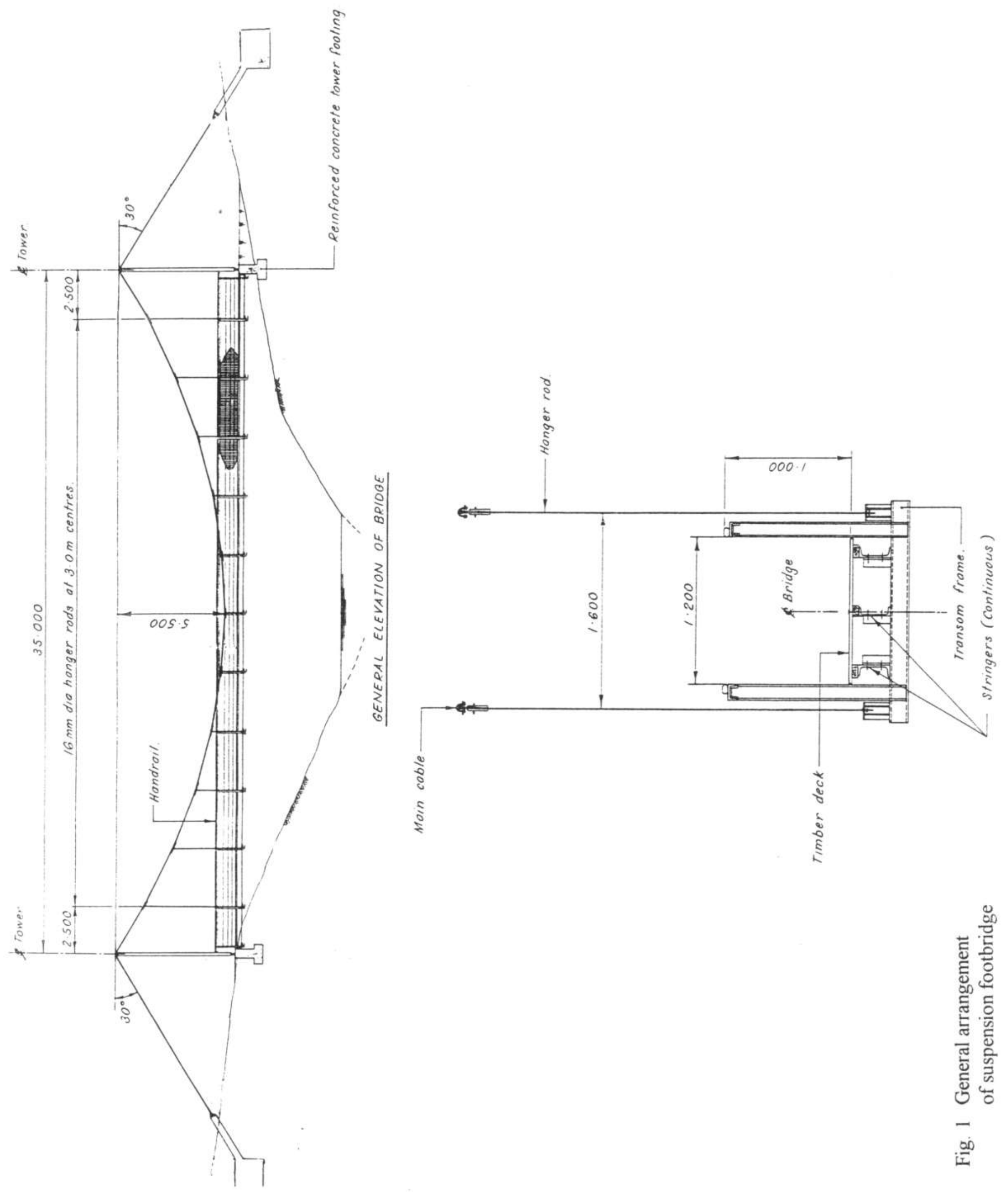


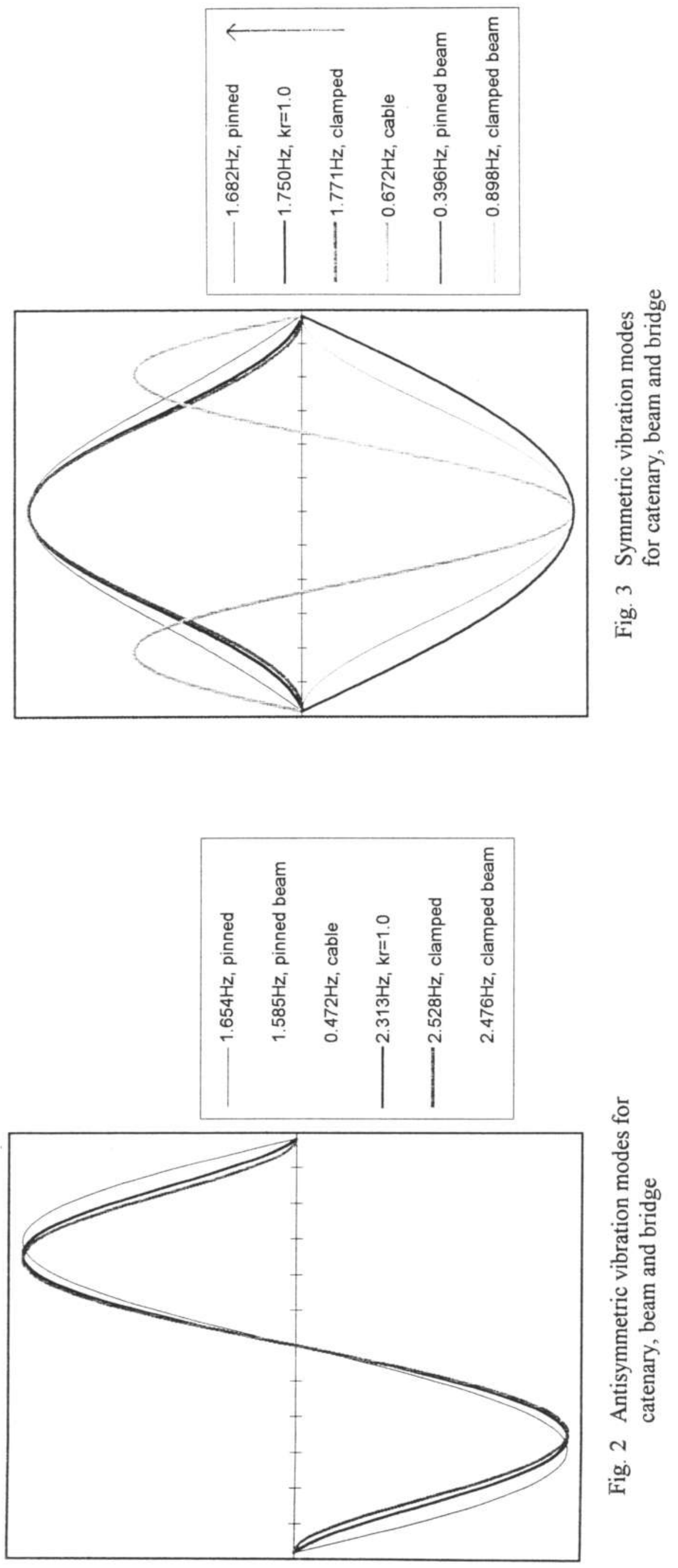




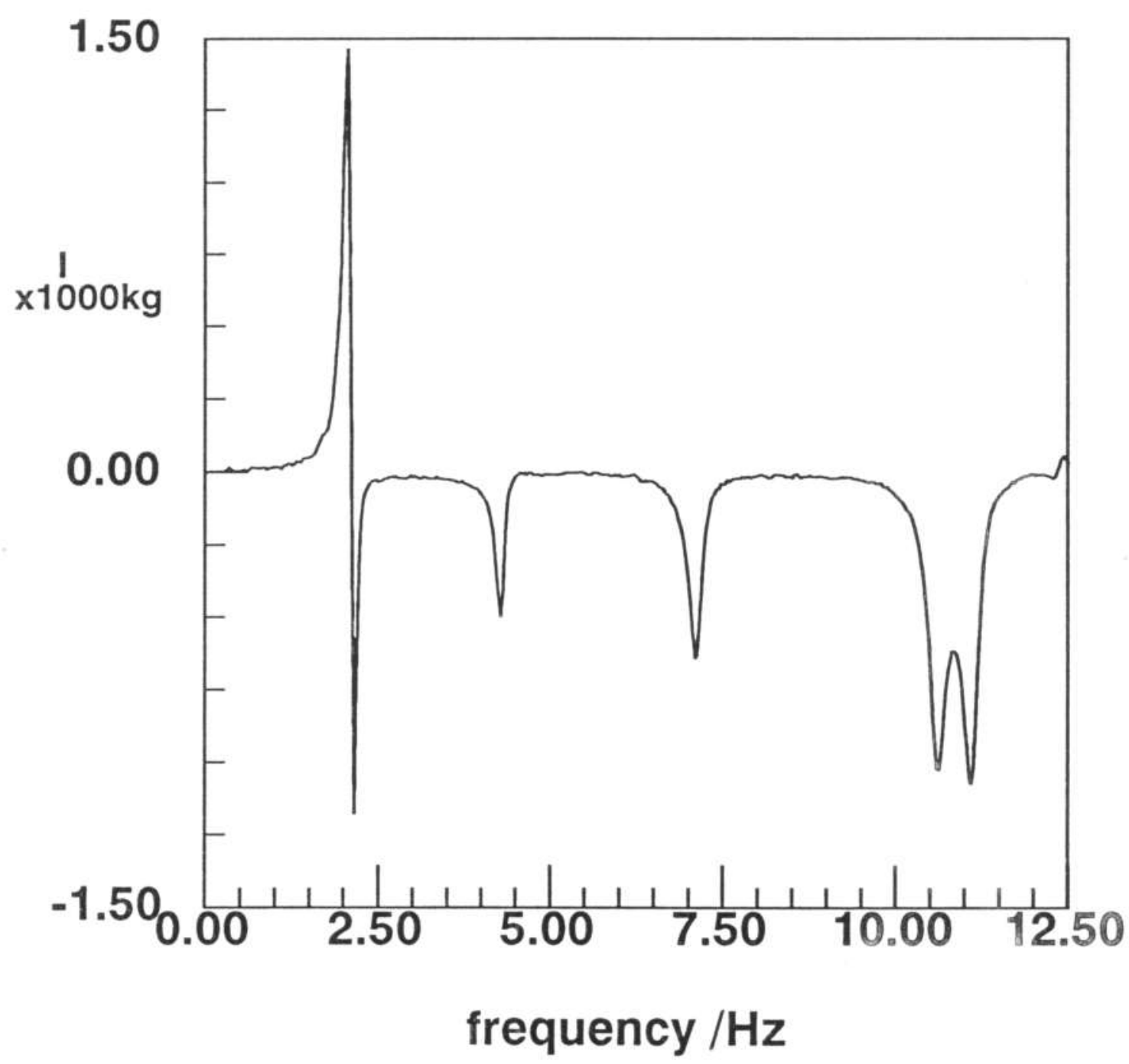

Fig. 4 Imaginary part of inertance function $I(\omega)$ 


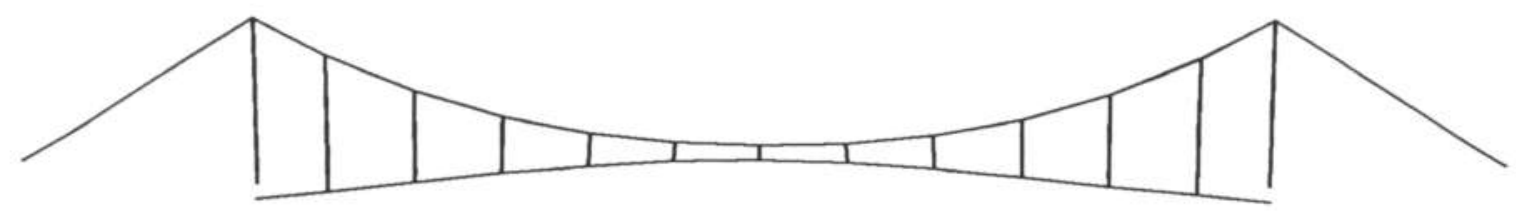

Mode VS1: $1.634 \mathrm{~Hz}$

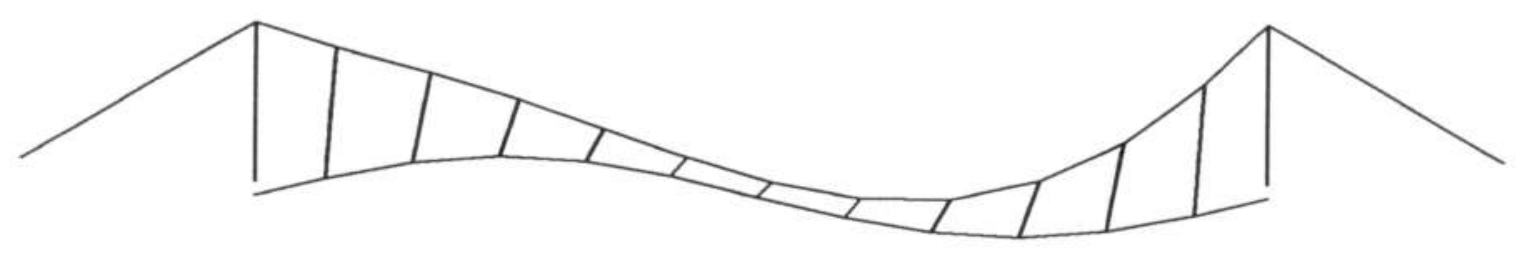

Mode VA1: $1.655 \mathrm{~Hz}$

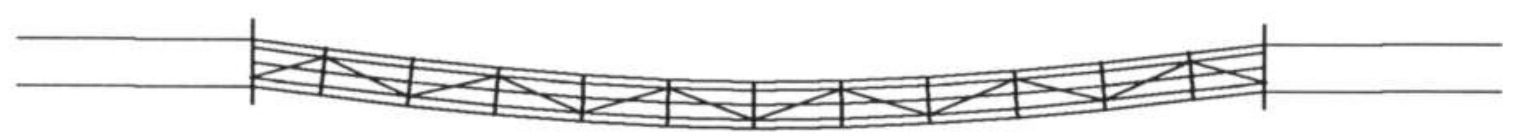

Mode LS1: $1.644 \mathrm{~Hz}$

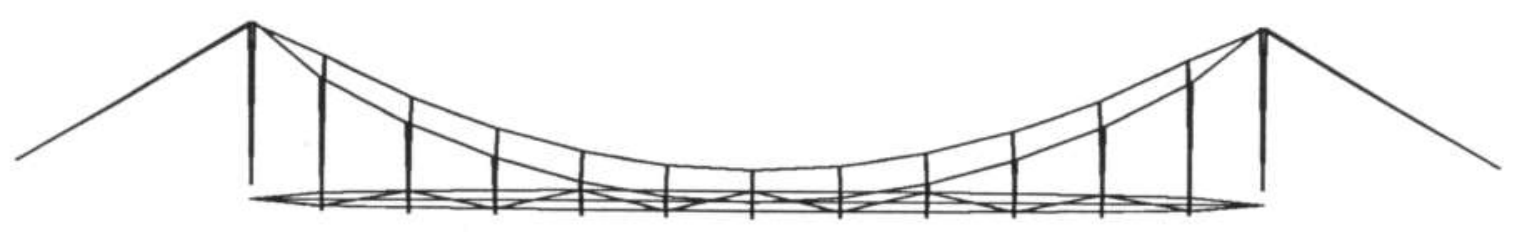

Mode TS1: $2.753 \mathrm{~Hz}$

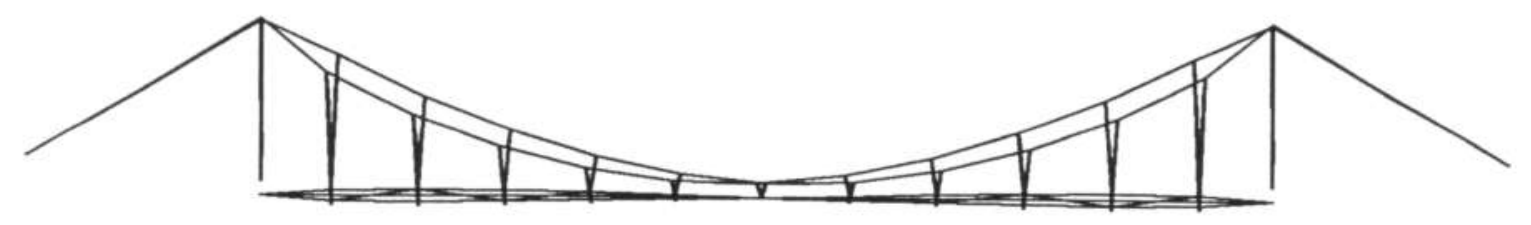

Mode TA1: $4.477 \mathrm{~Hz}$

Fig. 5 Modes predicted by 3D FE model (from design data with $\mathrm{k}_{\mathrm{r}}=0$ ) 


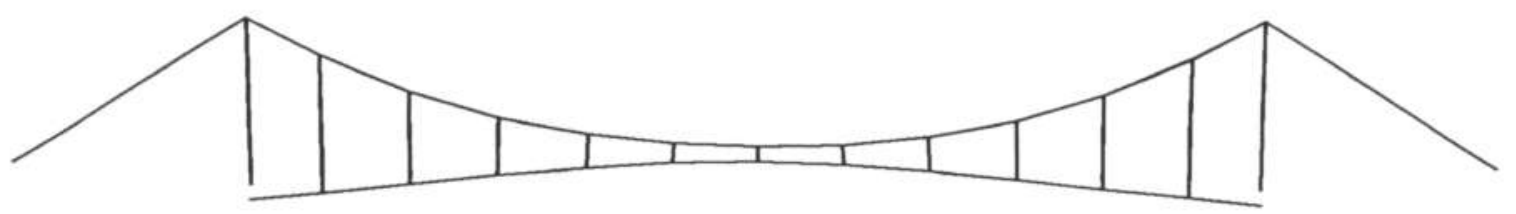

Mode VS1: $1.634 \mathrm{~Hz}$

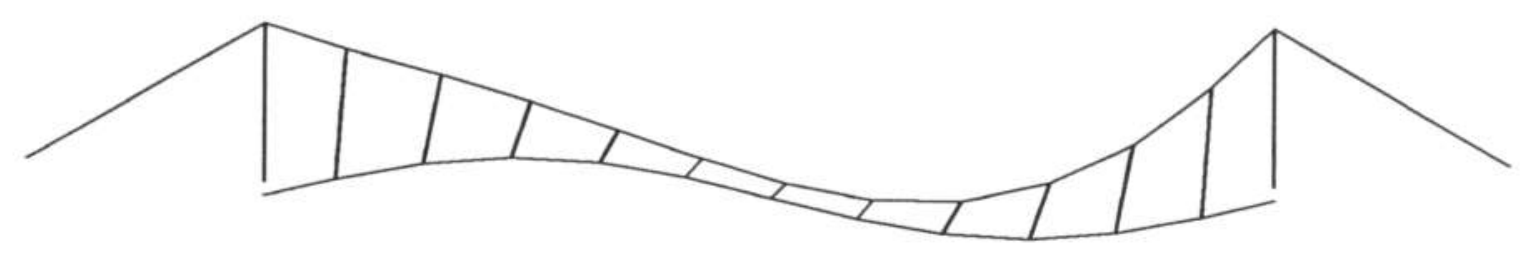

Mode VA1: $1.655 \mathrm{~Hz}$

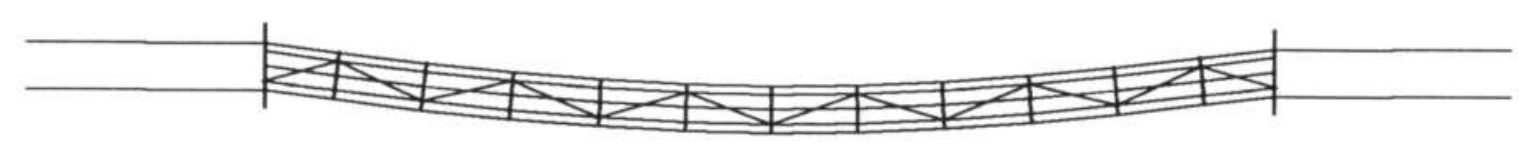

Mode LS1: $1.644 \mathrm{~Hz}$

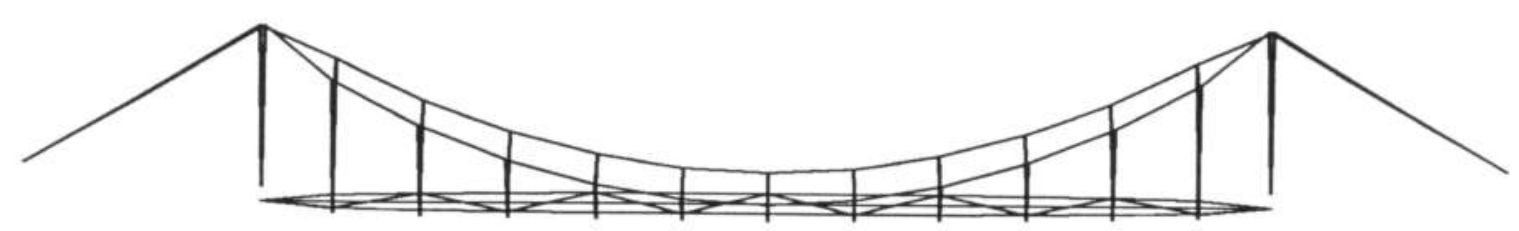

Mode TS1: $2.753 \mathrm{~Hz}$

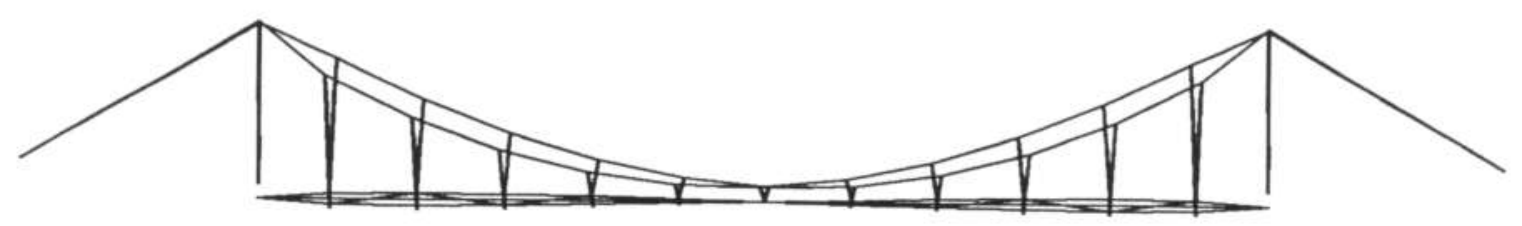

Mode TA1: $4.477 \mathrm{~Hz}$

Fig. 5 Modes predicted by 3D FE model (from design data with $\mathrm{k}_{\mathrm{r}}=0$ ) 

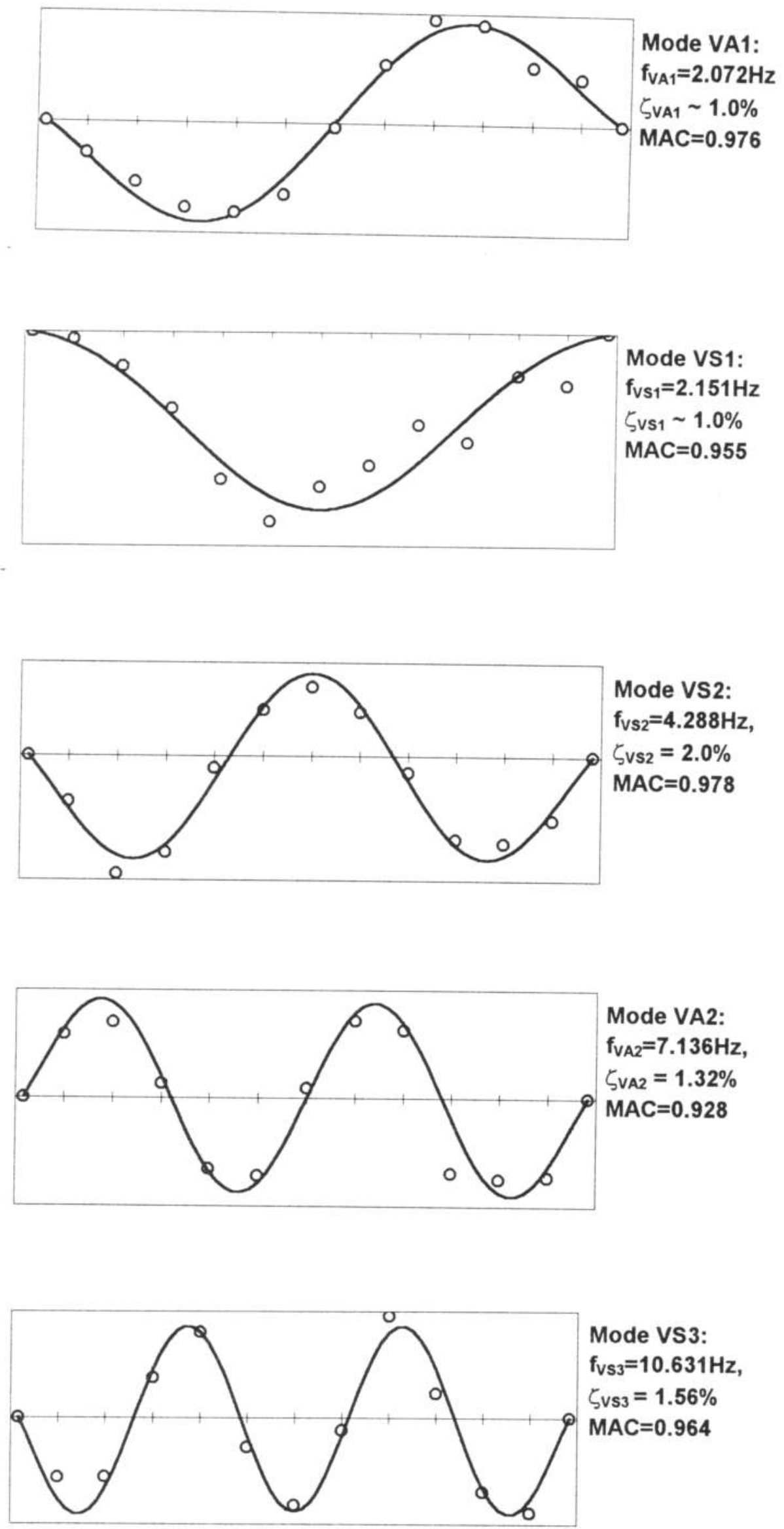

Fig. $b_{6}$ Comparison of theoretical mode shapes from DP model with experimental values (circles) 


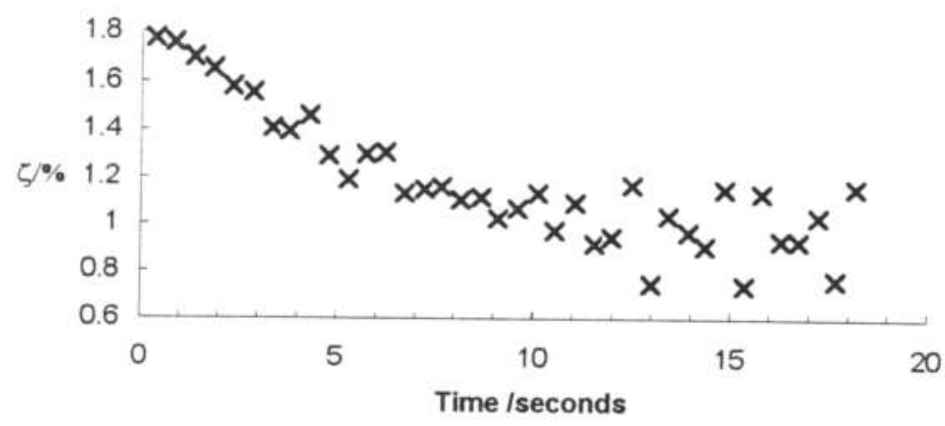

Fig. 6 Damping values for mode VAl obtained by logarithmic decrement during free decay 


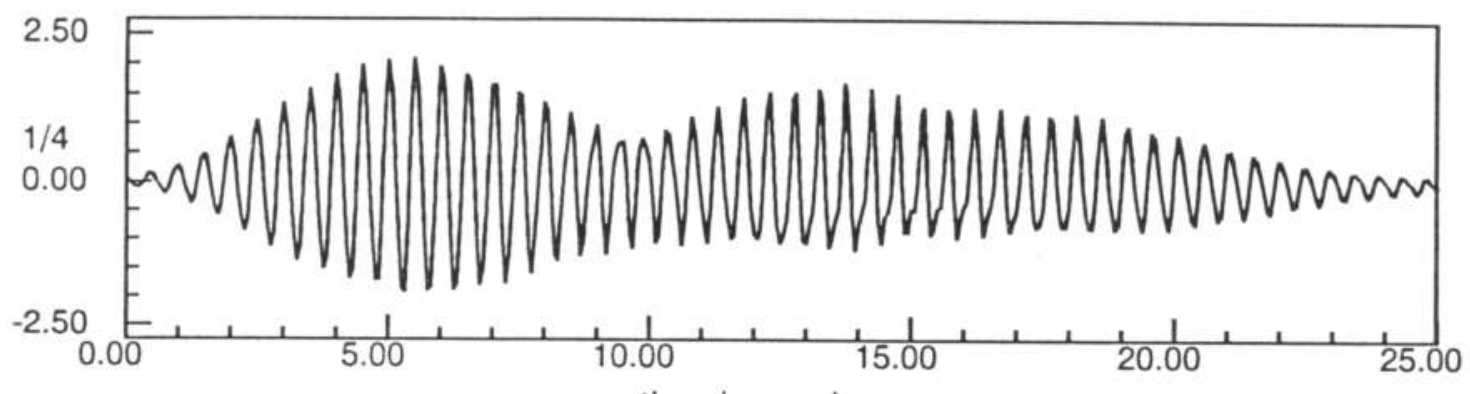

a) time /seconds

b)

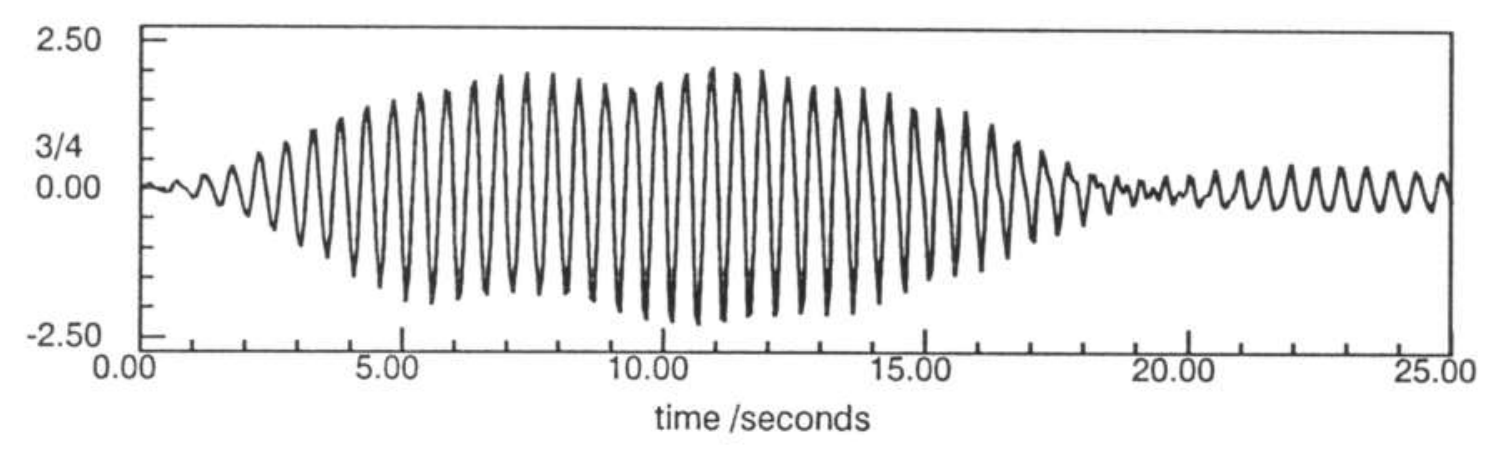

c)

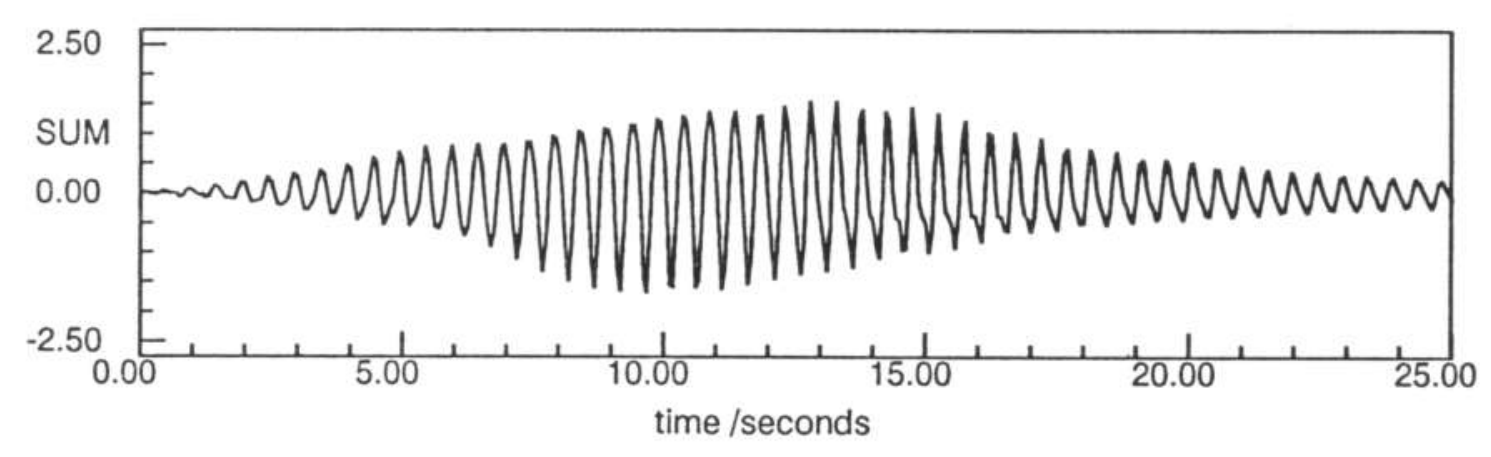

d)

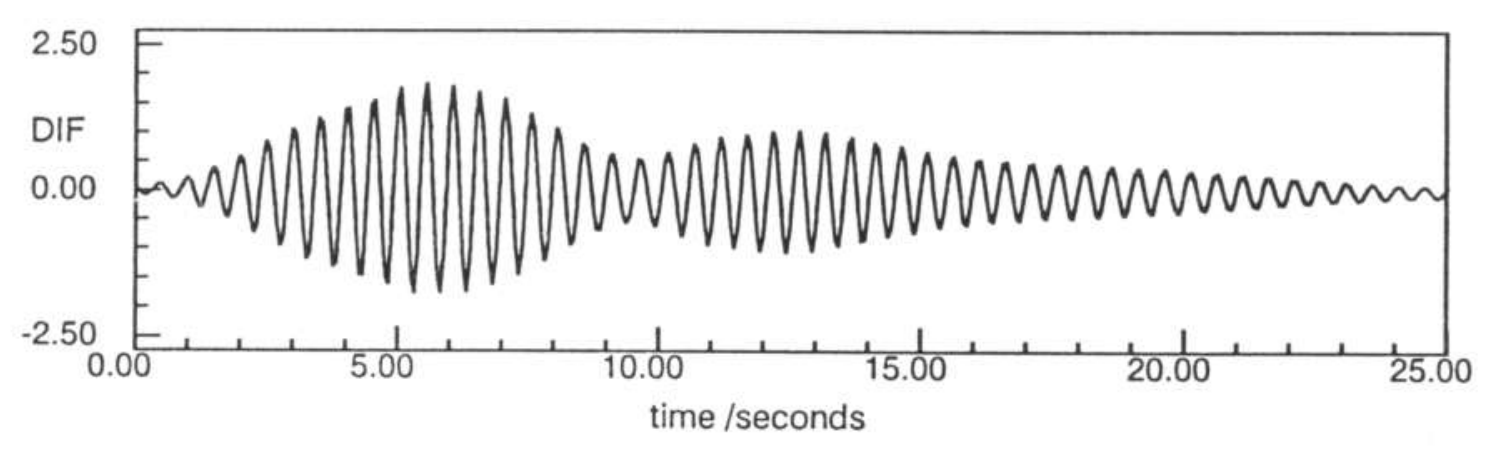

Fig. $7_{8}$ Measured vibration acceleration response (in $\mathrm{m} / \mathrm{sec}^{2}$ ) due to passage of 'pedestrian' 


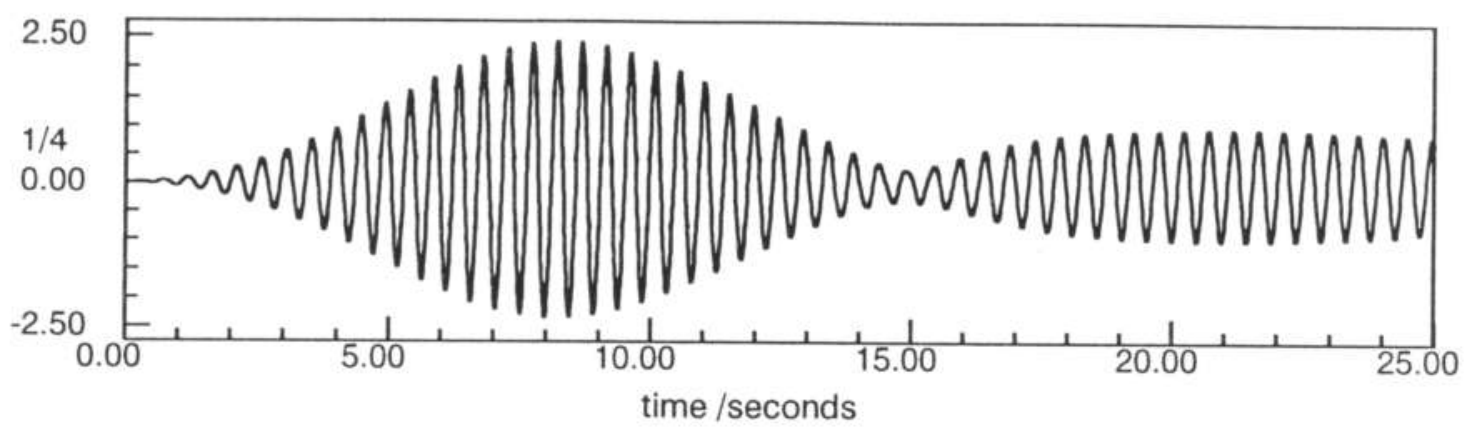

a)

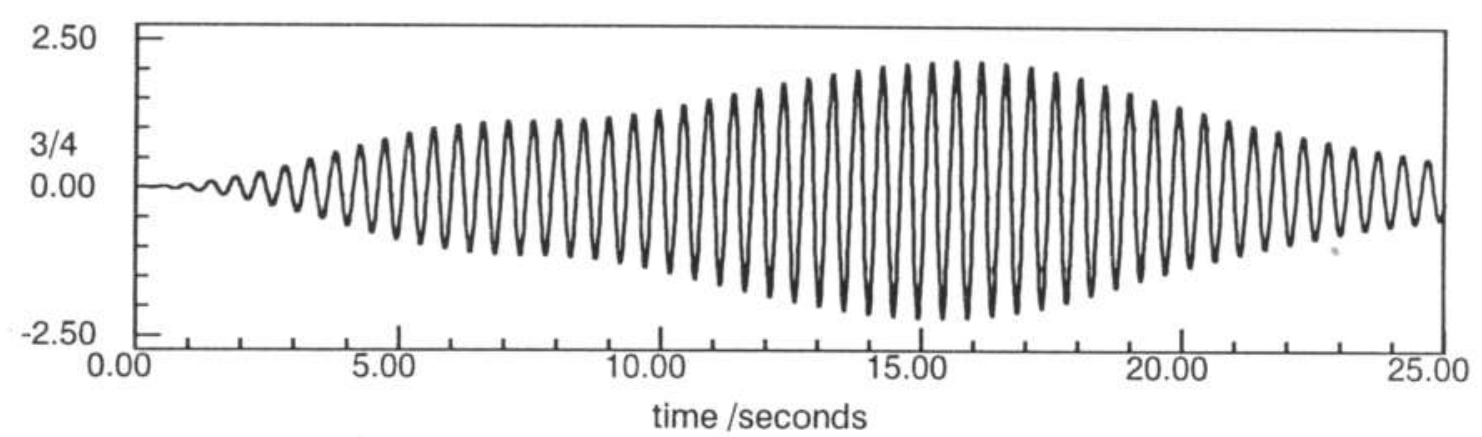

c)

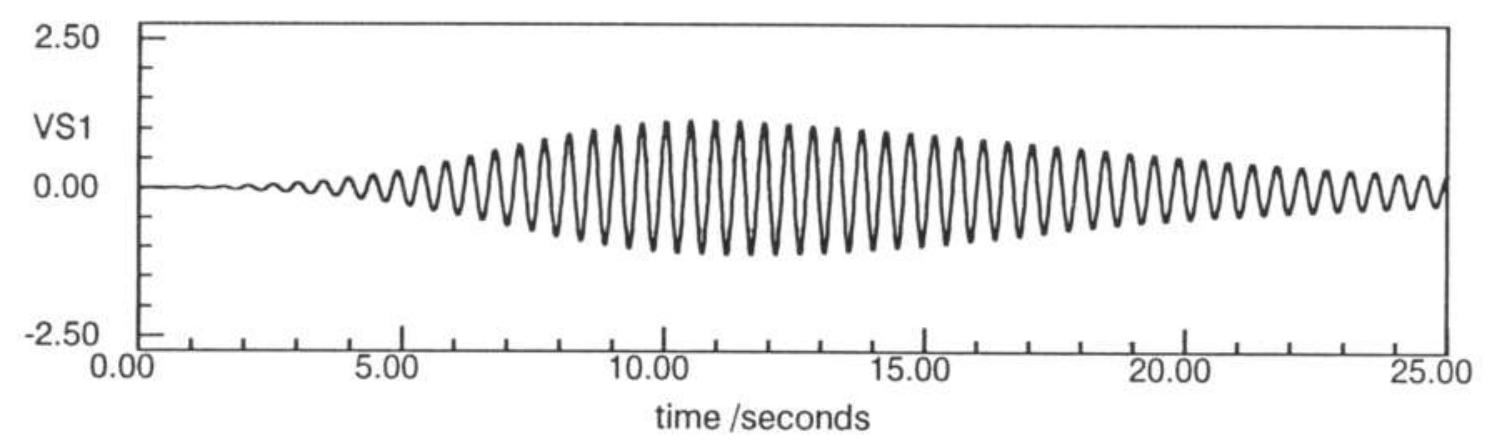

d)

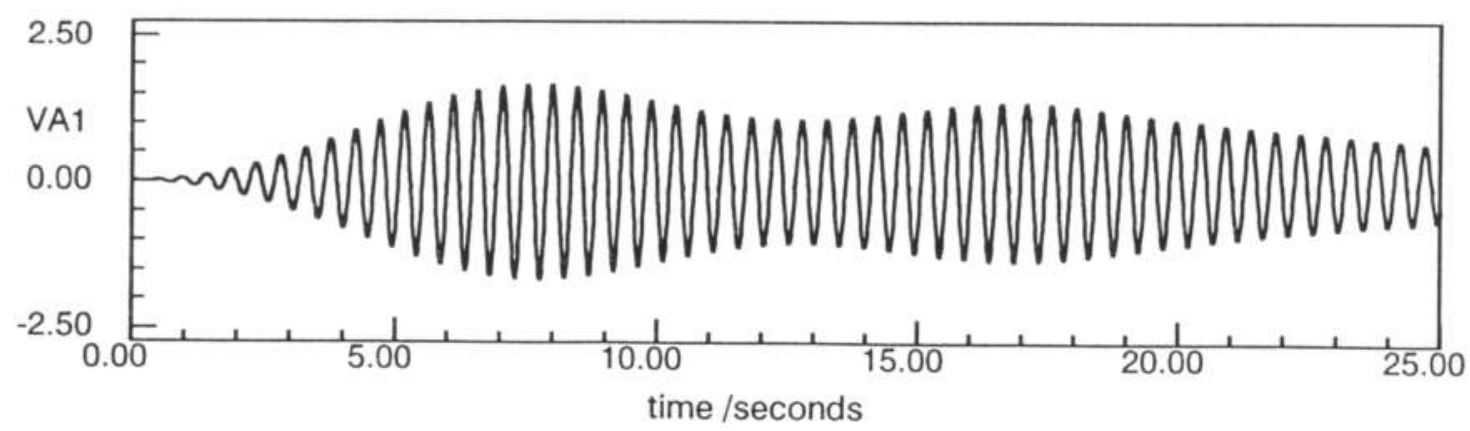

Fig. of Simulated vibration acceleration response (in $\mathrm{m} / \mathrm{sec}^{2}$ ) due to passage of pedestrian 